\title{
1 Effects of beta- and gamma-band rhythmic stimulation on motor inhibition
}

3 Inge Leunissen ${ }^{1,2}$, Manon Van Steenkiste ${ }^{1}$, Kirstin-Friederike Heise ${ }^{1,6}$, Thiago Santos Monteiro ${ }^{1,6}$, Kyle

4 Dunovan ${ }^{3}$, Dante Mantini ${ }^{1,4}$, James P. Coxon ${ }^{5 *}$, Stephan P. Swinnen ${ }^{1,6^{*}}$

5

$6 \quad{ }^{*}$ James P. Coxon and Stephan P. Swinnen should be considered joint senior author

$7 \quad{ }^{1} \mathrm{KU}$ Leuven, Department of Movement Sciences, Movement Control and Neuroplasticity Research

8 Group, Belgium

$9 \quad{ }^{2}$ Section Brain Stimulation and Cognition, Department of Cognitive Neuroscience, Faculty of

10 Psychology and Neuroscience, Maastricht University, The Netherlands.

$11{ }^{3}$ Department of Psychology, and Center for the Neural Basis of Cognition, Carnegie Mellon

12 University, Pittsburgh, Pennsylvania 15213

$13{ }^{4}$ Brain Imaging and Neural Dynamics Research Group, IRCCS San Camillo Hospital, Venice, Italy

$14{ }^{5}$ School of Psychological Sciences and Turner Institute for Brain and Mental Health, Monash University,

15 Melbourne, Australia

$16 \quad{ }^{6} \mathrm{KU}$ Leuven Brain Institute (LBI), KU Leuven, Belgium

17

18 Corresponding author:

19 Inge Leunissen

20 Oxfordlaan 55

$216229 \mathrm{EV}$, Maastricht

22 The Netherlands

23 E-mail: inge.leunissen@maastrichtuniversity.nl 


\section{Abstract}

2 Voluntary movements are accompanied by an increase in gamma-band oscillatory activity $(60-100 \mathrm{~Hz})$

3 and a strong desynchronization of beta-band activity $(13-30 \mathrm{~Hz})$ in the motor system at both the

4 cortical and subcortical level. Conversely, successful motor inhibition is associated with increased beta

5 power in a fronto-basal-ganglia network. Intriguingly, gamma activity also increases in response to a

6 stop-signal. In this study, we used transcranial alternating current stimulation to drive beta and

7 gamma oscillations to investigate whether these frequencies are causally related to motor inhibition.

8 We found that $20 \mathrm{~Hz}$ stimulation targeted at the pre-supplementary motor area enhanced inhibition

9 and increased beta oscillatory activity around the time of the stop-signal in trials directly following

10 stimulation. In contrast, $70 \mathrm{~Hz}$ stimulation seemed to slow down the braking process, and

11 predominantly affected go task performance. These results demonstrate that the effects of tACS are

12 state-dependent and that especially fronto-central beta activity is a functional marker for successful

13 motor inhibition. 


\section{Introduction}

Inhibitory control, such as the ability to suppress an already initiated movement, is essential in everyday life. Successful motor inhibition activates a distributed network of cortical and subcortical areas in which the pre-supplementary motor area (preSMA), the right inferior frontal cortex (rIFC) and the subthalamic nucleus (STN) have been identified as key nodes (Aron et al., 2016; Jahanshahi et al., 2015). However, the exact nature of the neural dynamics within this fronto-basal-ganglia network are not entirely clear. Long-distance neural communication is thought to arise from groups of neurons engaging in rhythmic synchronization (Fries, 2005). In the human motor system two main natural rhythms have been identified. On both a cortical and subcortical level gamma-band oscillatory activity $(60-100 \mathrm{~Hz})$ increases during voluntary movement (Crone et al., 1998; Litvak et al., 2012), suggesting it has a prokinetic role. In contrast, oscillatory activity in the beta-band $(13-30 \mathrm{~Hz})$ is prominent during tonic contractions, and decreases prior to and during movement (Engel \& Fries, 2010; Schmidt et al., 2019). Excessive beta oscillations, as in Parkinson's disease, are associated with slowing of movement and rigidity (Kuhn et al., 2004; Little \& Brown, 2014). This has led to the idea that beta activity might promote the inhibition of movement.

Indeed, electrophysiological recordings have revealed increased beta oscillations in preSMA, rIFC and STN during successful motor inhibition (Alegre et al., 2013; Castiglione et al., 2019; Huster et al., 2017; Kuhn et al., 2004; Ray et al., 2012; Swann et al., 2009; Swann et al., 2012; Wagner et al., 2018; Wessel et al., 2013; Wessel et al., 2016). Crucially, this activity was seen after the presentation of a stop-signal, but before the completion of the stop process (as indexed by the stop-signal reaction time; SSRT). Yet, others reported that beta oscillations primarily increase after the SSRT (Fischer et al., 2017; Jha et al., 2015), or without differentiation between successful and unsuccessful stops (Fonken et al., 2016). These authors suggest that fronto-subthalamic beta activity is not necessary for stopping, 
that is typically observed on trials that follow a stop signal (Bissett \& Logan, 2012). Thus controversy exists over the role of beta oscillatory activity in successful inhibition. would expect them to decrease during successful inhibition. While there is some evidence for decreased gamma-band power (Alegre et al., 2013), most intracranial electrophysiology studies have reported a brief increase centered around $70 \mathrm{~Hz}$ in response to a stop-signal. This phenomenon has been observed in the preSMA, rIFC (Bartoli et al., 2018; Fonken et al., 2016; Swann et al., 2012) and the STN (Fischer et al., 2017; Ray et al., 2012). Generally, this increased gamma activity was present regardless of the success of stopping, but before SSRT (but see Fischer et al., 2017). It is unclear if it reflects an attentional signature for detecting the stop-signal or if it might be involved in the actual implementation of the inhibitory process. nature. It is therefore not possible to infer whether beta or gamma oscillations are causally involved in motor inhibition. Investigation of causal oscillation-function relationships requires experimental control over the strength and/or phase of the ongoing brain rhythms. This can be achieved with transcranial alternating current stimulation (tACS) (Helfrich et al., 2014; Herrmann et al., 2016; Thut et al., 2011). Gamma-band tACS $(70 \mathrm{~Hz})$ over the primary motor cortex (M1) increases movement amplitude, force development and velocity (Guerra et al., 2018; Joundi et al., 2012; Moisa et al., 2016). Whereas, beta-band stimulation $(20 \mathrm{~Hz})$ over M1 results in reduced movement output (Guerra et al., 2018; Joundi et al., 2012; Pogosyan et al., 2009; Wach et al., 2013). Only one previous study assessed the effects of beta- and gamma-band tACS on motor inhibition. Joundi et al. (2012) found that $20 \mathrm{~Hz}$ tACS over M1 promotes inhibition of unintended movements in the context of a go/no-go task, but $70 \mathrm{~Hz}$ stimulation did not influence inhibitory performance. In a go/no-go task either a go cue or a no-go cue is presented, therefore performance on the task likely reflects action restraint, i.e. the decision to respond or not, rather than the ability to inhibit 
are presented on a minority of the trials after the participant has already begun to initiate their response to the go cue. Thus, stop-signal paradigms are better suited to assess the ability to cancel an already initiated action. In addition, the paradigm lends itself well to models of action cancellation such as the dependent process model (DPM)(Dunovan et al., 2015; Dunovan \& Verstynen, 2019). Which can provide insight in whether beta and gamma stimulation affect performance through modulation of the go and/or stop process. is triggered upstream of M1. Given the fronto-central topography of beta power during stopping, the goal of the present study was to stimulate preSMA instead of the M1 target used previously. Furthermore, if gamma oscillations observed in the preSMA for successful stops are causally related to the inhibitory process, then gamma stimulation of preSMA might also promote inhibition. To test our hypotheses, we delivered short trains of tACS while participants performed an anticipated response stop-signal paradigm. We hypothesized that beta, and possibly also gamma stimulation targeting preSMA would facilitate response inhibition, i.e. reduce SSRT. in modulating oscillatory brain activity could come from changes in neurophysiological measures. Most evidence so far depends on resting-state measures obtained directly after tACS. For example, the after-effects of alpha tACS are thought to rely on plasticity-related changes evoked by spike-timing dependent plasticity (STDP) (Zaehle et al., 2010). While it has been shown that beta and gamma tACS can affect cortical excitability and inhibition (Heise et al., 2016; Nowak et al., 2018; Wischnewski et al., 2019b), the after-effects on spectral power are unknown. Ideally one would be able to assess changes in oscillatory activity during tACS, however it remains unresolved whether the tACS artifact can be proficiently removed from concurrent magneto- and electroencephalography (M/EEG) recordings (Neuling et al., 2017; Noury \& Siegel, 2018). Here, we opted to use an intermittent tACS design which allows for the comparison between EEG spectral power in trials directly following stimulation with those further removed from the stimulation. This approach avoids the tACS artifact 
1 in the EEG yet is less dependent on plasticity related changes. We hypothesized that the increased

2 spectral power due to tACS entrainment might still be visible in the first few seconds after stimulation, but then fade away.

Finally, we performed individual simulations of the electric fields during tACS based on the registered electrode placement and individual MRI scans to assess whether the prospective behavioral effects of the stimulation follow a dose-response relationship.

\section{Results \& Discussion}

9 The main aim of this study was to investigate the role of beta- and gamma-band oscillations in motor inhibition. To this end, we used tACS over preSMA to entrain the $20 \mathrm{~Hz}$ (beta) and $70 \mathrm{~Hz}$ (gamma) frequencies. In accordance with previous literature we hypothesized beta stimulation to have an inhibitory effect on motor output during both going and stopping. In contrast, we reasoned that $70 \mathrm{~Hz}$ stimulation over the preSMA might facilitate movement on go trials, yet also promote inhibition during stop trials. All participants tolerated the stimulation well as indicated by the low ratings of discomfort and fatigue and the ratings did not differ between the two stimulation sessions (Supplementary Table 1).

\section{Task performance}

The independent race model used to estimate SSRT assumes that the distribution of the finishing times of the go process is the same on go and stop trials (context independence). In practice, this means that the average goRT should be higher than the average RT on failed stop trials, i.e. only the fastest go processes are able to escape inhibition. One participant was excluded from all further analyses due to violation of this assumption (Verbruggen et al., 2019). The number of errors on go trials was matched between stimulation frequencies $\left(F_{(1,102)}=0.14, p=0.71\right)$, and stimulated versus non-stimulated trials $\left(F_{(1,102)}=0.04, p=0.85\right)($ Table 1$)$. The dynamic tracking procedure resulted in a stop success rate close to $50 \%$ in both stimulation sessions (no main effect of 
Table 1. Effect of stimulation on stop-signal task performance.

\begin{tabular}{|c|c|c|c|c|c|c|c|c|c|}
\hline \multirow[b]{2}{*}{$\begin{array}{l}\text { Trial } \\
\text { type }\end{array}$} & & \multirow[b]{2}{*}{$\begin{array}{c}20 \mathrm{~Hz} \\
\text { Non-stimulated }\end{array}$} & \multirow[b]{2}{*}{$\begin{array}{c}20 \mathrm{~Hz} \\
\text { Stimulated }\end{array}$} & \multirow[b]{2}{*}{$\begin{array}{c}70 \mathrm{~Hz} \\
\text { Non-stimulated }\end{array}$} & \multirow[b]{2}{*}{$\begin{array}{c}70 \mathrm{~Hz} \\
\text { Stimulated }\end{array}$} & \multicolumn{4}{|c|}{ LME statistics } \\
\hline & & & & & & $\begin{array}{c}\mathrm{df}, \\
\text { Error df }\end{array}$ & $\begin{array}{c}\text { Main effect of } \\
\text { frequency } \\
(2 \mathrm{OHz}, 70 \mathrm{~Hz})\end{array}$ & $\begin{array}{l}\text { Main effect of } \\
\text { stimulation } \\
\text { (ON, OFF) }\end{array}$ & $\begin{array}{r}4 \\
\text { Interaction } 5 \\
6\end{array}$ \\
\hline \multirow{3}{*}{ Go } & $\begin{array}{c}\text { \% early } \\
\text { response }\end{array}$ & 0.0 & 0.0 & 0.0 & 0.0 & NA & NA & NA & NA \\
\hline & $\begin{array}{c}\% \text { no } \\
\text { response }\end{array}$ & $1.7 \pm 2.29$ & $1.57 \pm 2.46$ & $1.56 \pm 2.24$ & $1.53 \pm 2.48$ & $\begin{array}{c}1 \\
102 \\
\end{array}$ & $\begin{array}{l}F=0.14 \\
p=0.705\end{array}$ & $\begin{array}{l}F=0.04 \\
p=0.851\end{array}$ & $\begin{array}{cr}\mathrm{F}=0.16 \\
\mathrm{p}=0.694\end{array}$ \\
\hline & goRT (ms) & $17.96 \pm 43.64$ & $16.90 \pm 43.73$ & $18.10 \pm 42.4$ & $17.15 \pm 42.6$ & $\begin{array}{c}1, \\
28138\end{array}$ & $\begin{array}{c}F=0.69 \\
p=0.407\end{array}$ & $\begin{array}{c}F=3.71 \\
p=0.054\end{array}$ & $\begin{array}{c}\mathrm{F}=0.011 \\
\mathrm{p}=0.96812\end{array}$ \\
\hline \multirow{3}{*}{ Stop } & $\begin{array}{l}\text { Stop fail RT } \\
(\mathrm{ms})\end{array}$ & $-1.5 \pm 34.09$ & $-2.40 \pm 34.14$ & $-2.47 \pm 33.74$ & $-2.00 \pm 33.24$ & $\begin{array}{c}1 \\
6937 \\
\end{array}$ & $\begin{array}{l}F=0.27 \\
p=0.606\end{array}$ & $\begin{array}{c}F=0.05 \\
p=0.818\end{array}$ & $\begin{array}{c}F=0.72 \\
p=0.395\end{array}$ \\
\hline & $\%$ inhibit & $51.26 \pm 0.58$ & $51.75 \pm 0.69$ & $51.38 \pm 0.64$ & $51.78 \pm 0.7$ & $\begin{array}{c}1, \\
102 \\
\end{array}$ & $\begin{array}{c}\mathrm{F}=0.8 \\
\mathrm{p}=0.359\end{array}$ & $\begin{array}{c}F=26.8 \\
p<.0001\end{array}$ & $\begin{array}{cc}F=0.3 & 16 \\
p=0.611 & 17\end{array}$ \\
\hline & $\mathrm{SSRT}(\mathrm{ms})$ & $189.4 \pm 12.42$ & $191.1 \pm 11.24$ & $193.36 \pm 12.22$ & $192.4 \pm 12.3$ & $\begin{array}{c}1, \\
102 \\
\end{array}$ & $\begin{array}{c}F=5.36 \\
p=0.023\end{array}$ & $\begin{array}{c}\mathrm{F}=0.1 \\
\mathrm{p}=0.748\end{array}$ & $\begin{array}{l}\mathrm{F}=1.3718 \\
\mathrm{p}=0.244 \quad 19\end{array}$ \\
\hline
\end{tabular}

GoRT and stop fail RT are expressed relative to the target (i.e. response $-800 \mathrm{~ms}$ ). Mean \pm standard deviation is reported. LME $=$ linear mixed model. Results for LME models are given as Type III sums of squares for sequentially fitted fixed effects. 
bioRxiv preprint doi: https://doi.org/10.1101/2020.12.11.422006; this version posted December $11,2020$. The copyright holder for this preprint (which was not certified by peer review) is the author/funder, who has granted bioRxiv a license to display the preprint in perpetuity. It is made available under aCC-BY-ND 4.0 International license.

1 in stimulated than non-stimulated trials $\left(F_{(1,102)}=26.8, p<.0001\right)$. Besides a real effect of stimulation this could also be caused by the difference in trial numbers between the conditions ( $40 \%$ of all trials were stimulated).

\section{$20 \mathrm{~Hz}$ stimulation reduced force production on stop-signal trials}

In corroboration with Joundi et al. (2012), the percent change calculations revealed that $20 \mathrm{~Hz}$

A

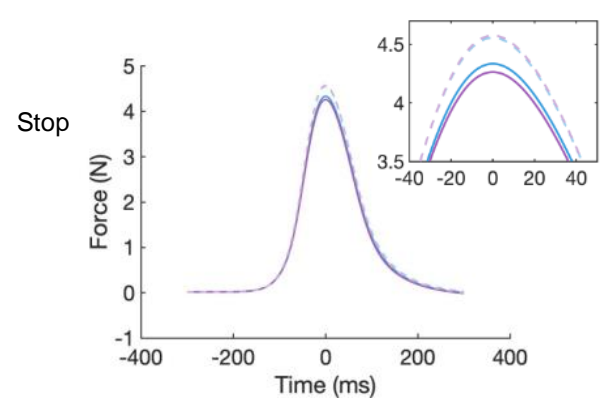

$-20 \mathrm{HzON} \cdots 20 \mathrm{HzOFF}-70 \mathrm{HzON} \cdots 70 \mathrm{~Hz}$ OFF

12 $\mathrm{PFR}=$ peak force rate.
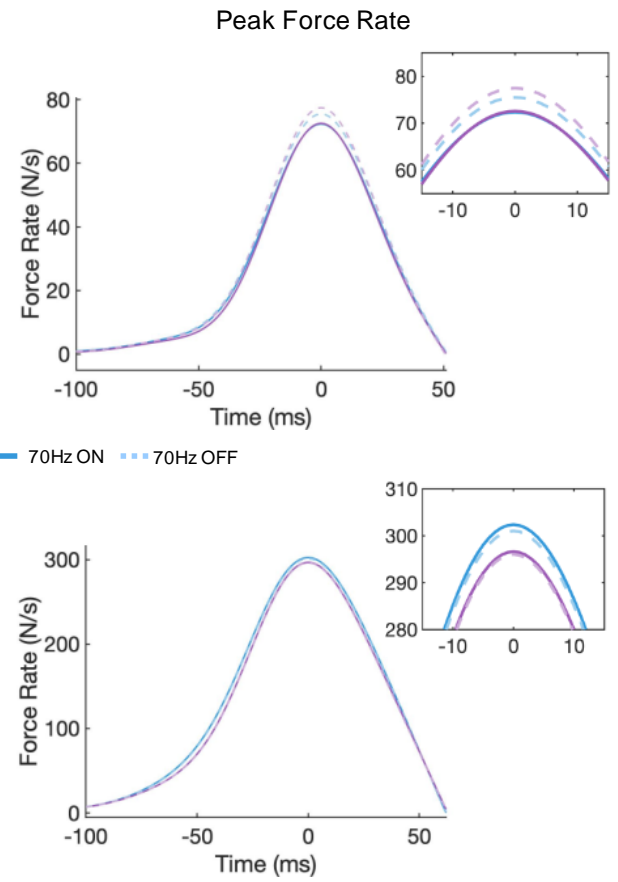

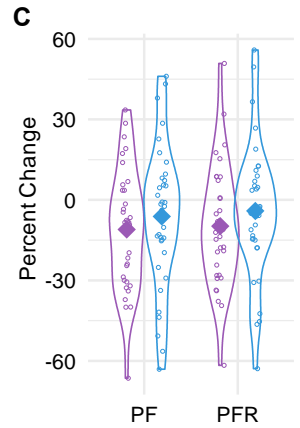

D

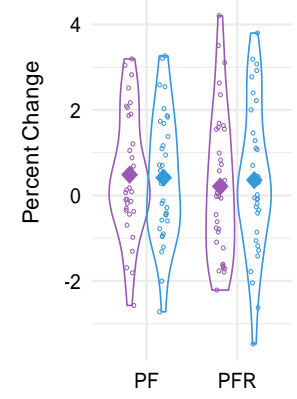

Figure 1. Grand averages for stop (A) and go (B) aligned to peak force and peak force rate for $20 \mathrm{~Hz}$ (purple) and $70 \mathrm{~Hz}$ (blue) stimulated (solid lines) and non-stimulated (dashed lines) trials. Sub-windows depict a zoomed view on the peaks. (C-D) Individual percent changes of peak force and peak force rate due to $20 \mathrm{~Hz}$ (purple) and $70 \mathrm{~Hz}$ (blue) stimulation on stop (C) and go (D) trials. Solid diamond shape represents the group mean. $P F=$ peak force, 
1 On go trials, $20 \mathrm{~Hz}$ stimulation did not affect peak force rate or the time to peak but did result in an

$20.48 \%$ increase in mean peak force (Table 2, Figure 1B,D). This might seem counterintuitive and contradicts the findings from Joundi et al. (2012). However, it has been demonstrated before that the response force on go trials increases with the increasing likelihood of a stop-signal appearing, in other words when the readiness to respond is low (van den Wildenberg et al., 2003). Analogous to the relationship between excessive beta oscillation and the bradykinesia and rigidity symptoms in PD (Kuhn et al., 2006), we speculate that $20 \mathrm{~Hz}$ stimulation puts a global break on the system, making it harder to respond when necessary. Therein also lies an important difference between the go/no-go task and our anticipated response stop-signal paradigm. In the go/no-go task there is no hard constraint on when to respond other than the experimenter's instruction to respond as fast as possible. As a result, participants tend to slow down until they gather enough evidence for going (Leunissen et al., 2017; Szmalec et al., 2009). Here, participants needed to perform a response at a known point in time, and on top of that there was visual feedback on their performance, reinforcing go task performance.

Higher force production on go trials in the $70 \mathrm{~Hz}$ stimulation session

Peak force and peak force rate were significantly higher in the $70 \mathrm{~Hz}$ than in the $20 \mathrm{~Hz}$ stimulation session (Table 2, Figure 1B). This effect seemed to be driven by the go trials (significant TRIAL TYPE* tACS FREQUENCY interaction; estimated difference in peak force on go trials: $1.06 \pm 0.06 \mathrm{~N}, z=16.53$, $p_{\text {adjusted }}<.0001$, stop trials: $-0.09 \pm 0.13 \mathrm{~N}, \mathrm{z}=-0.691, p_{\text {adjusted }}=0.896$; estimated difference in mean peak force rate on go trials: $6.12 \pm 0.92 \mathrm{~N} / \mathrm{s}, \mathrm{z}=6.68, p_{\text {adjusted }}<.0001$, stop trials: $-2.23 \pm 1.86 \mathrm{~N} / \mathrm{s}, \mathrm{z}=-1.2$, $\left.p_{\text {adjusted }}=0.617\right)$. The percent change calculations show that peak force on stimulated go trials in the $70 \mathrm{~Hz}$ stimulation session was $0.42 \%$ higher than peak force on the non-stimulated go trials. This increase was not significant however $(p=0.1)$. Since there was no effect of stimulation ON/OFF or a separate sham session it is impossible to infer whether the difference in force on go trials between the $20 \mathrm{~Hz}$ and $70 \mathrm{~Hz}$ session is caused by a decrease due to $20 \mathrm{~Hz}$ stimulation or an increase due to $70 \mathrm{~Hz}$ 
Table 2. Force outcomes on Go and successful Stop trials, with $20 \mathrm{~Hz}$ or $70 \mathrm{~Hz}$ stimulation ON or OFF.

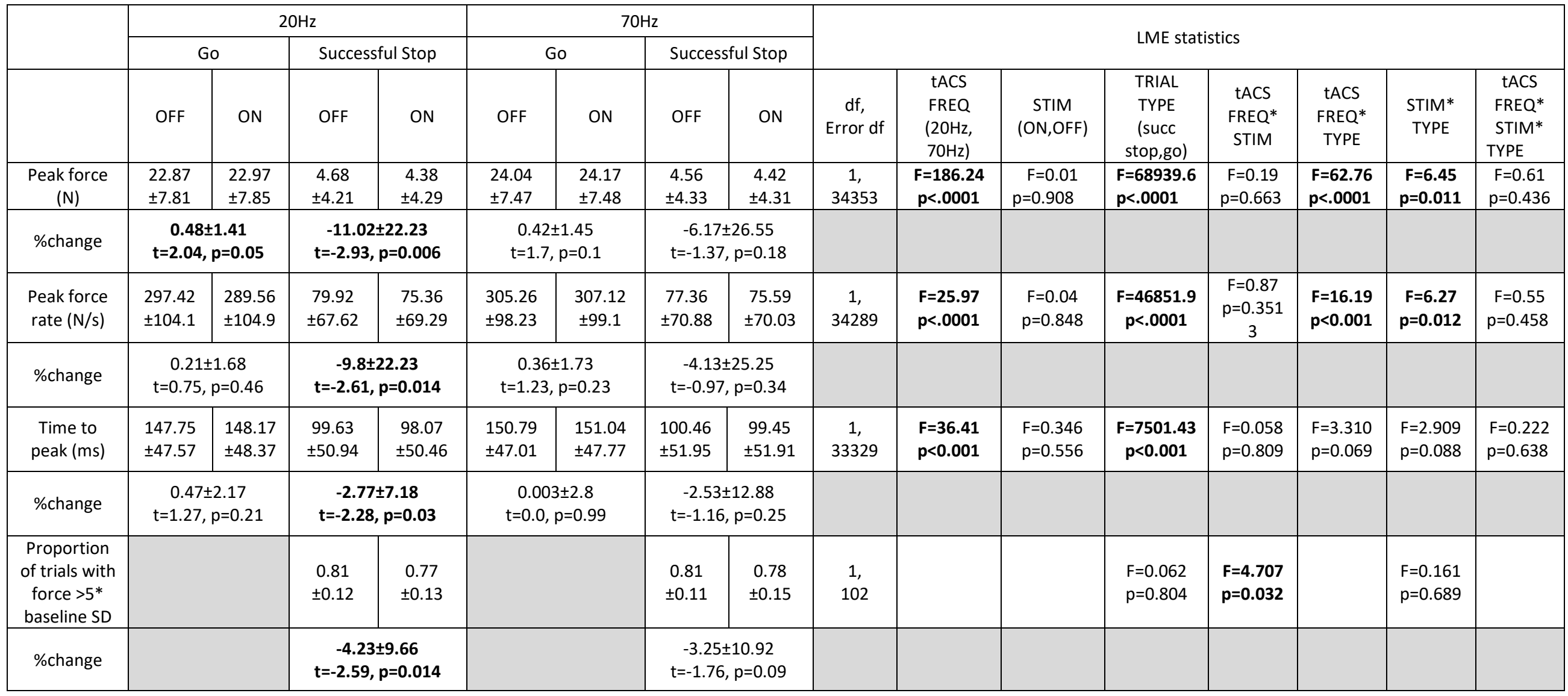

3 Mean \pm standard deviation is reported. LME = linear mixed model. Results for LME models are given as Type III sums of squares for sequentially fitted fixed effect 
1 stimulation. Based on the findings from Joundi et al. (2012), the most likely scenario is perhaps a

2

3

4 combination of both.

The lack of differences between stimulated and non-stimulated go trials in the $70 \mathrm{~Hz}$ stimulation session could be caused by several factors. First, the go task involves a timed response rather than a reaction to an external cue. It is possible that gamma oscillations are less involved in timed responses. Second, the preSMA and SMA-proper are thought to be responsible for linking situations with appropriate actions (Nachev et al., 2008). Hosaka et al. (2016) demonstrated that gamma oscillatory activity in the (pre)SMA of monkeys increased during movement, but particularly when the action plan needed to be updated. Finally, given the significant difference in peak force and peak force rate between the $20 \mathrm{~Hz}$ and $70 \mathrm{~Hz}$ stimulation session it is also possible that the stimulation effects carried over to the non-stimulated trials (see tACS aftereffects section for a more in-depth discussion).

\section{Opposing effects of $20 \mathrm{~Hz}$ and $70 \mathrm{~Hz}$ stimulation on braking drift rate}

No difference was observed in goRT between the different stimulation frequencies or stimulation ON/OFF, although the latter showed a trend towards shorter response times (i.e. closer to the target) with stimulation $\mathrm{ON}$ in both the $20 \mathrm{~Hz}$ and $70 \mathrm{~Hz}$ stimulation session $\left(\mathrm{F}_{(1,28138)}=3.71, p=0.054\right)($ Table 1$)$. This might be related to the increased force and velocity observed in go trials during stimulation, as discussed above. The absence of a stimulation effect on goRT corroborates the findings of Pogosyan et al. (2009) and Joundi et al. (2012).

SSRT was significantly shorter in the $20 \mathrm{~Hz}$ than in the $70 \mathrm{~Hz}$ stimulation session $\left(\mathrm{F}_{(1,102)}=5.36\right.$, $p=0.023)$, but there was no difference between SSRT estimated from stimulated and non-stimulated trials, or a FREQUENCY*STIMULATION interaction. Again, this precludes us from concluding whether $70 \mathrm{~Hz}$ stimulation increased SSRT or $20 \mathrm{~Hz}$ stimulation decreased SSRT.

SSRT is an estimate of the covert latency of the stop signal estimated based on the independent race model (Logan et al., 1984). Conceptualizing the go and stop processes as independent processes racing against each other has accounted well for the observed behavioral data 
bioRxiv preprint doi: https://doi.org/10.1101/2020.12.11.422006; this version posted December 11, 2020. The copyright holder for this preprint (which was not certified by peer review) is the author/funder, who has granted bioRxiv a license to display the preprint in perpetuity. It is made available under aCC-BY-ND 4.0 International license.

1 in the stop-signal paradigm (Matzke, 2018). However, on a neural level it is evident that the neurons

2 involved in movement initiation and inhibition interact with each other during action cancellation

3 (Boucher et al., 2007; Munoz \& Schall, 2003; Schmidt et al., 2013). Behavioral models that include such

4 a dependency between the go and stop process indeed provide an even better fit to the data (Boucher

5 et al., 2007; Dunovan et al., 2015). In the dependent process model (DPM) from Dunovan et al. (2015;

6 2019) the go process is modelled as a stochastic accumulator that gathers evidence at a certain drift-

7 rate $\left(v_{e}\right)$, leading to a response when it crosses an upper threshold (a) (Figure 2).

A

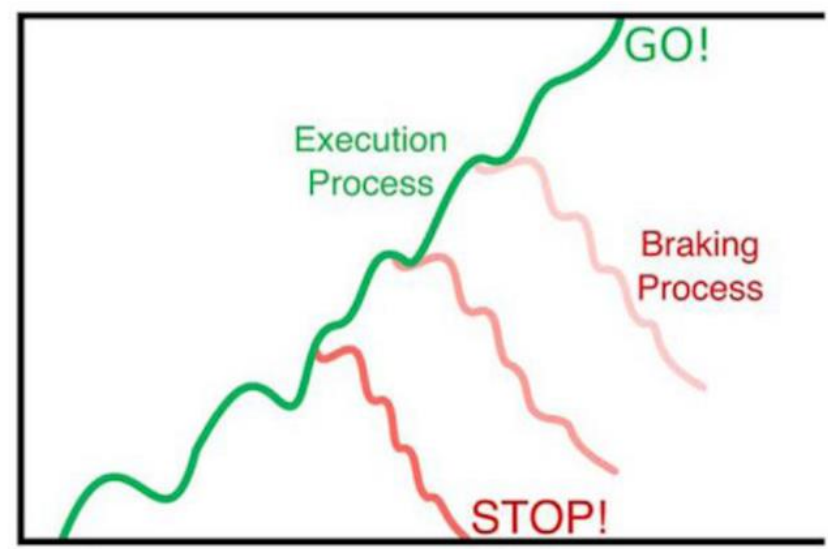

B Execution Drift-Rate
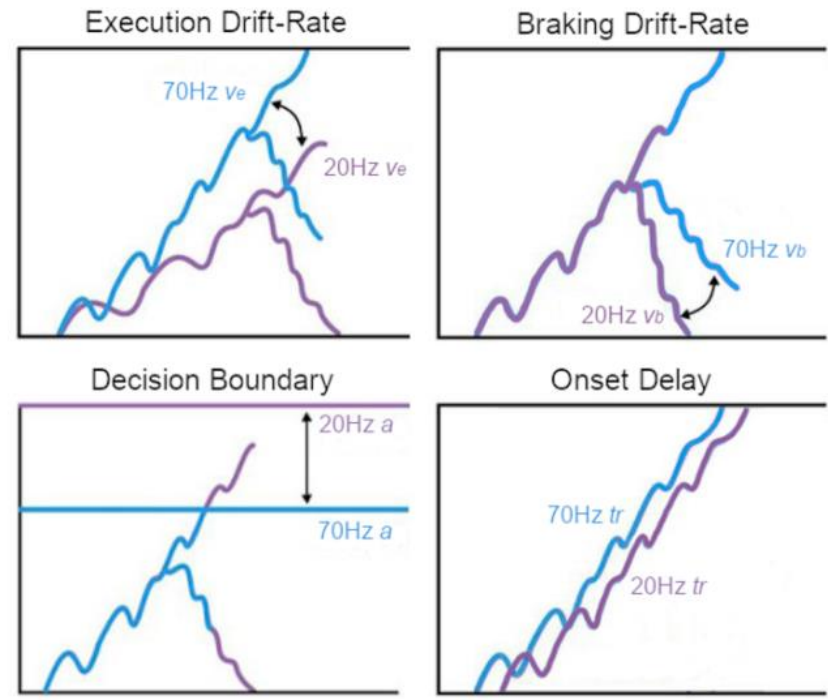

Figure 2. Graphical description of the dependent process model (DPM). (A) The DPM assumes that the state of an accumulating execution process at the time of the stop-signal determines the initial state of the braking process, making it more difficult to cancel actions closer to the execution boundary. (B) Possible control mechanisms that could be altered by beta $(20 \mathrm{~Hz})$ and/or gamma $(70 \mathrm{~Hz})$ tACS stimulation. Adapted with permission from Dunovan and Verstynen (2019). 
bioRxiv preprint doi: https://doi.org/10.1101/2020.12.11.422006; this version posted December $11,2020$. The copyright holder for this preprint (which was not certified by peer review) is the author/funder, who has granted bioRxiv a license to display the preprint in perpetuity. It is made available under aCC-BY-ND 4.0 International license.

In the event of a stop-signal, a second braking process is instantiated at the current state of the execution process and must reach the bottom boundary before the execution threshold is reached in order to cancel motor output. This model not only provides a better fit to the data, but also gives insight into the mechanisms underlying going and stopping. Another advantage is that the DPM takes into account the full goRT and failed stop RT distributions. Even though there was no difference in average goRT and SSRT between stimulated and non-stimulated trials, stimulation might have altered the shape of the response distributions. By fitting the DPM differences in shape can be picked up and are reflected in a change in the rate of the execution $\left(v_{e}\right)$ or braking drift $\left(v_{b}\right)$, shift the onset time at which the execution process begins to accumulate (tr), or change the distance to the threshold $(a)$. The braking drift modulation model best explained the effect of stimulation on task performance (Figure 3, Table 3). Braking drift rate increased due to $20 \mathrm{~Hz}$ stimulation, whereas $70 \mathrm{~Hz}$ stimulation decreased the braking drift rate (note that more negative values reflect a stronger braking process). Although the braking drift modulation model provided the best fit to the data the other models also had very good fits, suggesting that stimulation might not solely affect braking drift.

Table 3. Dependent process model parameter estimates and fit statistics.

\begin{tabular}{|c|c|c|c|c|c|c|c|c|}
\hline & $\begin{array}{c}\text { Flat } \\
\text { model }\end{array}$ & $\begin{array}{c}2 \mathrm{~Hz} \\
\text { Non- } \\
\text { stimulated }\end{array}$ & $\begin{array}{c}20 \mathrm{~Hz} \\
\text { Stimulated }\end{array}$ & $\begin{array}{c}70 \mathrm{~Hz} \\
\text { Non- } \\
\text { stimulated }\end{array}$ & $\begin{array}{c}70 \mathrm{~Hz} \\
\text { Stimulated }\end{array}$ & AIC & BIC & $\begin{array}{c}\Delta \text { with } v_{b} \\
\text { model }\end{array}$ \\
\hline$v_{e}$ & 1.198 & 1.197 & 1.197 & 1.997 & 1.999 & -782.939 & -773.411 & 14.485 \\
\hline$v_{b}$ & -1.052 & -1.054 & -1.064 & -1.053 & -1.016 & -797.424 & -787.896 & \\
\hline$a$ & 0.443 & 0.439 & 0.443 & 0.442 & 0.434 & -789.094 & -779.656 & 8.24 \\
\hline$t r$ & 0.44996 & 0.44996 & 0.44996 & 0.44999 & 0.44969 & -792.392 & -782.864 & 5.032 \\
\hline
\end{tabular}

Best fit parameter estimates for braking drift rate $\left(v_{b}\right)$, execution drift rate $\left(v_{e}\right)$, boundary height $(a)$ and onset delay ( $t r)$. The last two columns show the Akaike information criterion (AIC), and Bayesian information criterion (BIC) as complexity penalized goodness-of-fit measures. Lower values in all three measures imply a better fit to the data. 
C
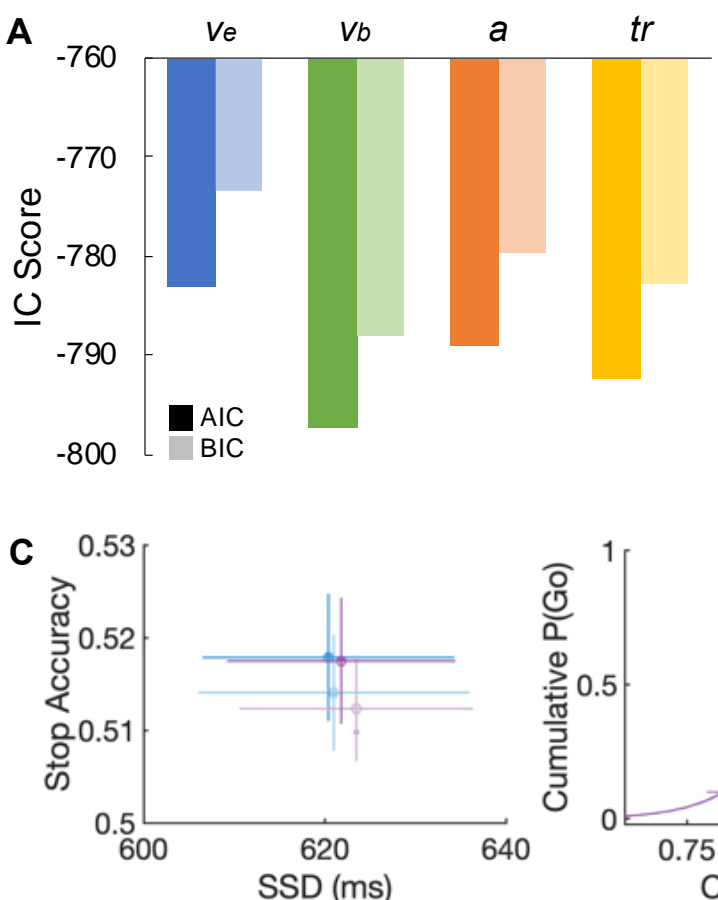
trials than go trials.
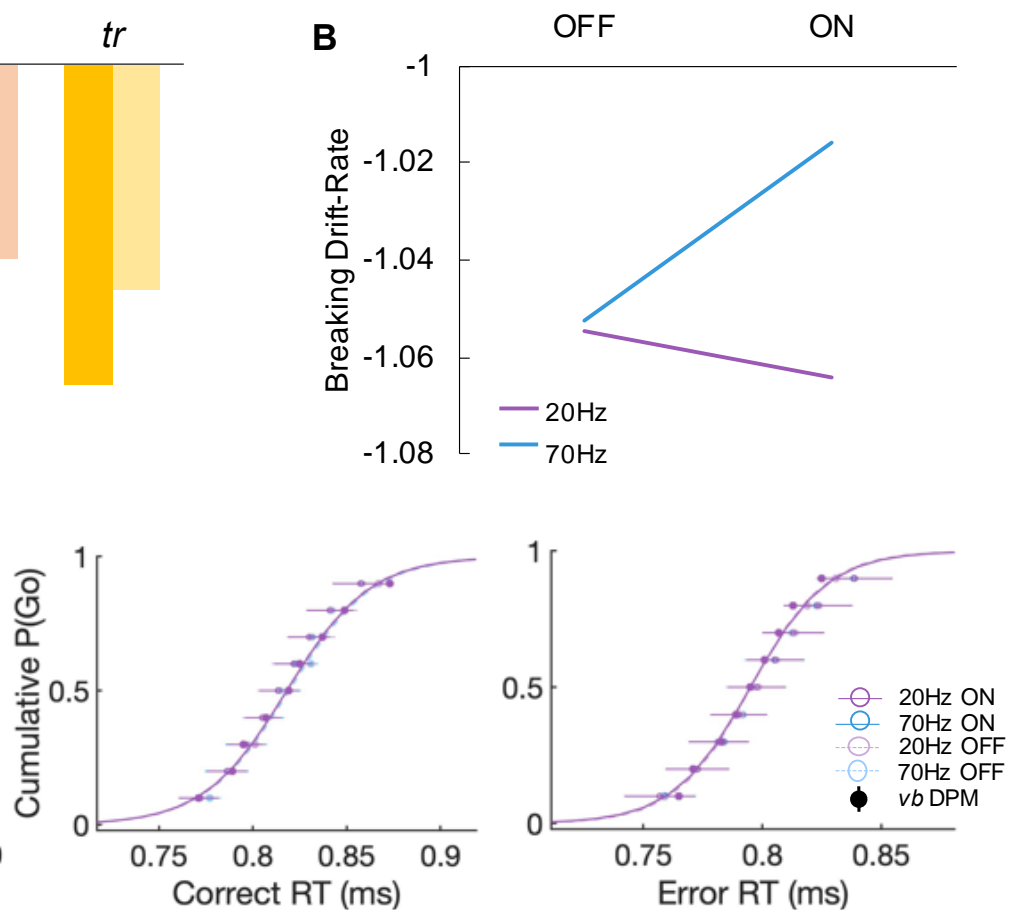

Figure 3. (A) Goodness-of-fit measures for the four different dependent process models. AIC (dark) and BIC (light) scores for all single-parameter models, allowing either execution drift-rate ( $v_{e} ;$ blue), braking drift-rate $\left(v_{b}\right.$; green), execution boundary height ( $a$; orange), or onset delay (tr; yellow) to vary across conditions. The model with the lowest score, in this case the braking drift modulation model, is preferred. (B) Parameter estimates of the braking drift rate in stimulated and non-stimulated trials in the beta $(2 \mathrm{OHz})$ and gamma $(7 \mathrm{OHz})$ sessions. (C) Model predicted data (solid lines and circles) simulated with best-fit parameters from the $v_{b}$ model overlaid on the average \pm SEM empirical data (transparent circles and horizontal lines).

Taken together, the results from the force and response time analyses show opposing roles for beta and gamma oscillations that fit with the prevailing view that gamma activity in the motor system is pro-kinetic, while beta oscillations support motor suppression. Stimulation interacts with the beta rhythm to drive oscillations, but the degree to which this resonance phenomenon takes place is dynamically determined by task demands, e.g. $20 \mathrm{~Hz}$ tACS had a much stronger effect on stop-signal

We did not find evidence for a causal role of gamma oscillations in stopping. Gamma stimulation even seemed to reduce the speed of the braking process, and rather affected go performance. Peak force and peak force rate were higher in the $70 \mathrm{~Hz}$ stimulation session. Moreover, the parameter estimates of the DPM's all point towards movement facilitation with $70 \mathrm{~Hz}$ stimulation (i.e. increased execution drift rate, lower boundary heights and shorter onset delay). Fischer et al. 
1 of movement rather than the stopping process per se. By using a task in which continuous ongoing

2 movement needs to be inhibited they circumvented this issue and, based on their findings, they

3 advocate that increased gamma and not beta activity is responsible for successful inhibition. We want

4 to emphasize that our paradigm was very successful in ensuring go response initiation, since the

5 proportion of successful stop trials in which we could still identify a force response 5 SD above baseline was on average $80 \%$ (range $50-100 \%$, Table 2) opposed to $~ 45 \%$ in Joundi et al. (2012). Therefore, we

$7 \quad$ find this explanation unlikely for our findings.

9 for long-distance communication between frontal cortex and the basal ganglia (Bartoli et al., 2018;

10 Swann et al., 2012). This long-distance communication might require less precise timing of the

11 entrainment. Because preSMA gamma-band activity increases for both going and stopping (albeit at

12 different timescales), stimulating at $70 \mathrm{~Hz}$ for the whole trial duration might create a conflict between

13 facilitating movement versus promoting inhibition.

\section{Sources of variability}

The behavioral results largely follow the hypothesized effects of stimulation. However, it is also evident that the effects are variable from one participant to the next. In an attempt to identify some possible sources of this variability we performed several explorative analyses.

The amount of current that reaches the targeted brain area likely influences the size of the stimulation effect. Stimulation was provided at a fixed output current of $1 \mathrm{~mA}$, but individual differences (e.g. in skull thickness and scalp to cortex distance) can influence how much current actually reaches the brain (Datta et al., 2012). To investigate whether there was a dose-response relationship between amount of current reaching the preSMA and the behavioral effect of stimulation we modelled the current flow in each individual based on the registered electrode positions and MRI scans. Two recent studies 
bioRxiv preprint doi: https://doi.org/10.1101/2020.12.11.422006; this version posted December $11,2020$. The copyright holder for this preprint (which was not certified by peer review) is the author/funder, who has granted bioRxiv a license to display the preprint in perpetuity. It is made available under aCC-BY-ND 4.0 International license.

1 provide validation for the accuracy of such models by using intracranial recordings (Huang et al., 2017;

2 Opitz et al., 2016). and that the field expansion was limited to the area between the four return electrodes (Figure 4A). The predicted normalized electrical field strength in the preSMA ROI during the beta session was significantly related to the percent change in peak force on successful stops $(r=-0.469, p=0.028)$ (Figure 4B). This dose-response relationship supports the notion that tACS stimulation has a causal effect on et al., 2020).

A

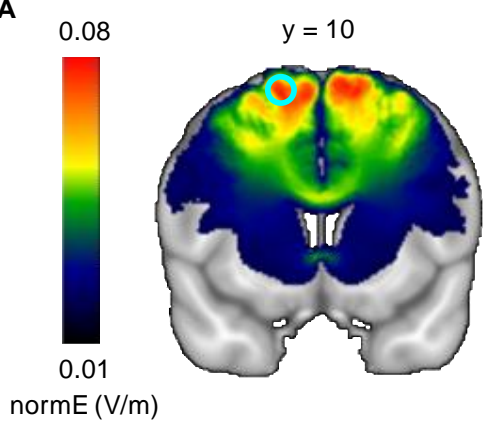

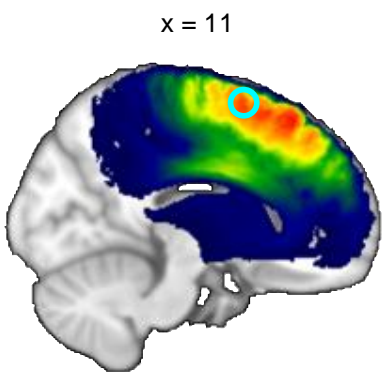

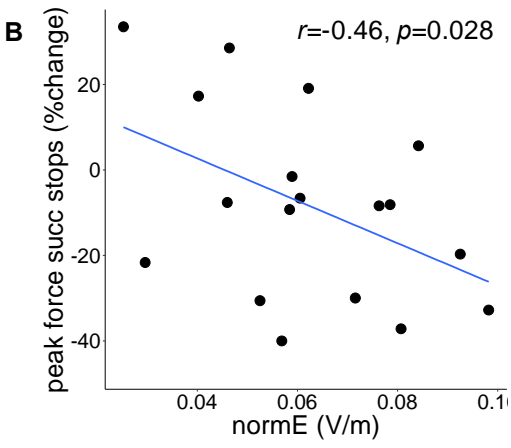

12

Figure 4. Simulation of the electrical field of the tACS. A) Group average of the normalized predicted electrical field distribution in MNI space. The cyan circle indicates the preSMA ROI (10mm sphere around coordinate $[11,10,62]$ based on a previous fMRI study with the same task paradigm). B) Relation between normalized predicted electrical field strength within the preSMA ROI and the effect of beta stimulation on peak force in successful stop trials. The shaded area represents the $95 \%$ confidence interval.

\section{Individual peak frequency}

Another possible source of variability is the stimulation frequency. The effects of tACS seem to follow an Arnold tongue principle in the sense that tACS can only modulate ongoing brain oscillations if the frequency of the tACS is very close to the frequency of the intrinsic brain oscillations. To be able to synchronize or entrain frequencies further away from the "Eigenfrequency" the external driving force (tACS) will need to be stronger (i.e. higher stimulation amplitude) (Ali et al., 2013). In this study we 
bioRxiv preprint doi: https://doi.org/10.1101/2020.12.11.422006; this version posted December $11,2020$. The copyright holder for this preprint (which was not certified by peer review) is the author/funder, who has granted bioRxiv a license to display the preprint in perpetuity. It is made available under aCC-BY-ND 4.0 International license.

1

2

3

4

5

6

7

8 clear individual peak.

chose to use $20 \mathrm{~Hz}$ and $70 \mathrm{~Hz}$ as stimulation frequencies because oscillatory activity in the motor system

is commonly centered around these frequencies (Chakarov et al., 2009; Fischer et al., 2017;

Muthukumaraswamy, 2010).

To evaluate whether individuals with a peak in beta oscillatory power close to $20 \mathrm{~Hz}$ responded more strongly to the stimulation than individuals with a peak frequency further removed from $20 \mathrm{~Hz}$, we identified the individual beta frequency based on the resting state EEG acquired before the beta stimulation session and plotted it against the percent change in force on successful stop trials. Figure 5 demonstrates that participants with a peak between $18-22 \mathrm{~Hz}$ typically showed a decrease in peak force on successful stops with beta stimulation for $23 / 27$ participants $(85 \%)$, whereas outside of that range $3 / 8$ participants (37\%) showed a decrease. This corroborates with findings from Vossen et al. (2015) who found the after effects of alpha stimulation to be the strongest at the individual alpha peak and not present $\pm 2 \mathrm{~Hz}$ away from the individual peak frequency. Note that a similar procedure is not possible for the gamma-band as the signal to noise ratio with scalp EEG makes it difficult to reliably uncover the higher frequencies and gamma-band activity is typically quite broad without a

Figure 5. Estimated individual beta peaks based on pre-stimulation resting EEG at electrode Fz plotted against percent change in peak force on successful stop trials with $20 \mathrm{~Hz}$ stimulation. Participants that fall within the grey shaded area (i.e. within $2 \mathrm{~Hz}$ from the stimulation frequency) tend to show improved inhibitory performance during $20 \mathrm{~Hz}$ stimulation. 
bioRxiv preprint doi: https://doi.org/10.1101/2020.12.11.422006; this version posted December 11, 2020. The copyright holder for this preprint (which was not certified by peer review) is the author/funder, who has granted bioRxiv a license to display the preprint in perpetuity. It is made available under aCC-BY-ND 4.0 International license.

1

11

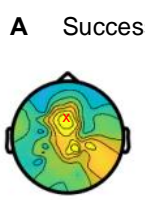

$150 \mathrm{~ms}$

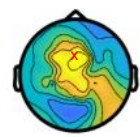

$200 \mathrm{~ms}$

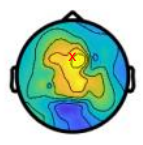

250ms

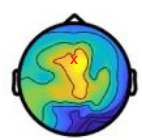

$300 \mathrm{~ms}$

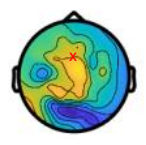

$350 \mathrm{~ms}$

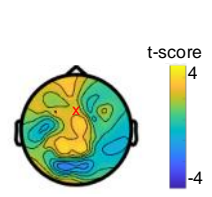

$400 \mathrm{~ms}$

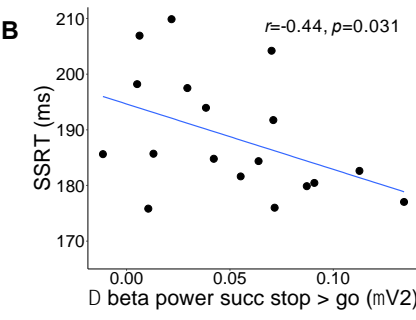

C

Post $>$ Pre

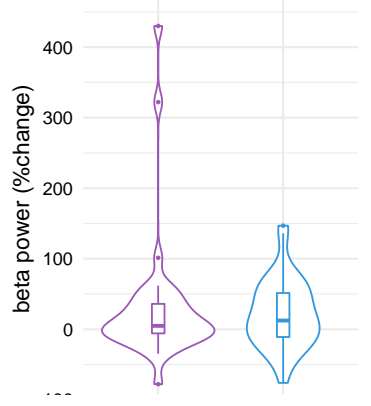

$20 \mathrm{~Hz} \quad 70 \mathrm{~Hz}$
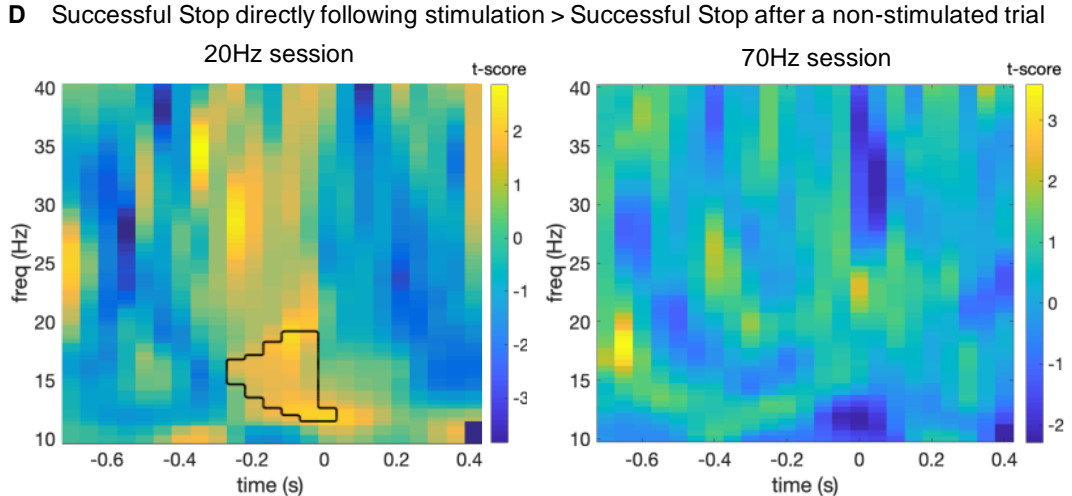

Figure 6. (A) Topographic distribution of increased beta activity in successful stops versus go trials $150-400 \mathrm{~ms}$ after the presentation of the stop signal. The red X marks the location of electrode Fz. (B) Correlation between the difference in beta power for successful stop and go trials and stop-signal reaction time (SSRT) in electrode Fz. The shaded area represents the $95 \%$ confidence interval. (C) Percent change in resting EEG beta power (13$30 \mathrm{~Hz}$ ) from pre to post stimulation. (D) Time-frequency power plots of the comparison between successful stop trials that directly followed stimulation and successful stop trials that occurred after a non-stimulated trial. The black outline represents the significant positive cluster. 
After-effect of beta stimulation is state-dependent

2 tACS effects have been shown to outlast the stimulation duration (Veniero et al., 2015). These aftereffects are thought to rely on changes occurring through spike-timing dependent plasticity (Veniero et al., 2015; Zaehle et al., 2010), rather than the entrainment of the oscillations which takes place online (Helfrich et al., 2014). For $20 \mathrm{~Hz}$ tACS, after-effects on cortical excitability have been found to last up to an hour (Wischnewski et al., 2019a). Here, beta oscillatory power at rest was enhanced after $20 \mathrm{~Hz}$ tACS (pre- versus post-test: $\mathrm{V}=418, \mathrm{p}=0.039$ ). However, this effect was also present in the $70 \mathrm{~Hz}$ stimulation condition ( $V=467, p=0.012)$, and the change in beta power from pre- to post-stimulation did not differ between the two stimulation frequencies ( $V=276, p=0.723$ ) (Figure 6C). This could mean that the increase in beta power is due to general processes such as performing the task, or that $70 \mathrm{~Hz}$ stimulation influenced beta power (de Hemptinne et al., 2013). Comparing successful stop trials directly following stimulation (i.e. stop-signal was presented $\sim 2.5 \mathrm{~s}$ after the end of the previous stimulation train) with successful stop trials following a nonstimulated trial (i.e. stop-signal was presented $\sim 7 \mathrm{~s}$ after the of end of the previous stimulation train) revealed one significant positive cluster with higher beta activity $250-50 \mathrm{~ms}$ before the presentation of the stop signal in trials directly following $20 \mathrm{~Hz}$ stimulation (Figure 6D). This effect was not present in the $70 \mathrm{~Hz}$ stimulation session. Under normal circumstances beta activity significantly increases after the presentation of the stop signal (Figure 6A)(Swann et al., 2012; Wagner et al., 2018; Wessel et al., 2016). The finding that stopping was successful when beta activity in preSMA was already increased $200 \mathrm{~ms}$ before the stop-signal (i.e. before participants knew they had to stop) suggests that beta stimulation increases proactive inhibition. The fact that beta activity was not enhanced during the entire period, but only around the time that a stop-signal could be expected, highlights that the (after) effects of tACS are state-dependent. These results also illustrate that the effects of our intermittent stimulation protocol carried over to the non-stimulated trials and likely clouded the differences between stimulation ON/OFF, similar to the offline effects reported in Heise et al. (2019). 


\section{Conclusion}

2 We provide evidence that fronto-central beta oscillatory activity is causal to stopping ability. During successful stop trials $20 \mathrm{~Hz}$ stimulation over preSMA resulted in a considerable decrease in force output and the response time models revealed that $20 \mathrm{~Hz}$ stimulation specifically increased braking drift. These effects followed a dose-response relationship with the strength of the individually simulated electric field. In contrast, $70 \mathrm{~Hz}$ stimulation seemed to lead to a decrease in braking drift and to mainly affect go task performance. Our results highlight the state-dependency of tACS entrainment and, along with recent complementary research (Sundby et al., 2020), pave the way for the use of fronto-central beta activity as a functional marker of motor inhibition.

\section{Methods}

\section{Participants}

12 Thirty-six right-handed (laterality quotient range 33-100, mean 90.5 (Oldfield, 1971)) healthy 13 volunteers (age range 19-28y, mean 22.5y, 15 male) were included in this study. Standard screening 14 verified that none of the participants presented with contraindications regarding non-invasive brain 15 stimulation (Bikson et al., 2009; Woods et al., 2016). All procedures were approved by the ethical 16 committee of the University Medical Center of the KU Leuven (protocol no. 57640) and written 17 informed consent was obtained from all participants.

\section{Experimental design}

Participants underwent two tACS-EEG sessions in which they received either $20 \mathrm{~Hz}$ (beta) or $70 \mathrm{~Hz}$ (gamma) stimulation during the performance of a stop-signal task. The stimulation frequency order was counterbalanced across participants, and sessions took place at least 48h apart (range 2-55 days, mean 10 days) to avoid potential carry-over effects. Data acquisition in each session started with 5 min of resting EEG with eyes open while fixating on a white fixation cross on a black background (pre$E E G$ ), and also ended with 3 min of resting EEG (post-EEG). 


\section{$1 \quad$ Stop-signal paradigm}

2 Participants performed an anticipated response stop-signal task (Coxon et al., 2006; Leunissen et al.,

3 2017; Slater-Hammel, 1960). They were comfortably seated at approximately $1 \mathrm{~m}$ distance of a computer screen (refresh rate $60 \mathrm{~Hz}$ ). The visual display consisted of a vertical indicator, presented centrally on the screen, that moved from the bottom upwards on each trial (Figure 7A). A target line was situated $800 \mathrm{~ms}$ from onset. The primary task was to stop the indicator at the target by pinching a force transducer (OMEGA Engineering, Norwalk, CT, USA) held between the index finger and thumb of the right hand (go trials). In line with Pogosyan et al. (2009) and Joundi et al. (2012) response force measures were taken, as the more detailed force kinematics were more sensitive to changes in behavior due to tACS stimulation than response times. Participants were instructed to perform these go trials as accurately and consistently as possible. To reinforce go task performance the color of the target line changed to green, yellow, orange or red at the end of each trial, depending on whether responses were within $20,40,60$, or $>60 \mathrm{~ms}$ of the target. In $33 \%$ of the trials the indicator stopped automatically prior to the target. When this happened, participants tried to prevent pressing the sensor (stop trials, Figure 7A). Separate staircasing algorithms were used for stimulated and nonstimulated trials to ensure convergence to $50 \%$ success on stop trials in each condition. The initial stop time was set at $250 \mathrm{~ms}$ from the target and was adjusted in steps of $25 \mathrm{~ms}$. The indicator was reset to empty after 1s. The inter-trial interval was $4.5 \mathrm{~s}$.

Before administration of the experimental task, participants were instructed to pinch the force transducer as hard as possible for $\sim 5$ seconds to determine maximal voluntary force (MVF) (custom LabVIEW software, National Instruments, Austin, TX, USA). This procedure was repeated 3 times, and the highest peak-force value was recorded. Next, participants were asked to pinch with a short but powerful pulse against the force transducer, as if they were responding to a stimulus. The response threshold was initially set to $35 \%$ of their MVF and lowered in steps of $5 \%$ till participants reported they could comfortably cross the threshold (range $20-35 \%$, mean $29 \%$ ) to avoid fatigue. The force signal was sampled at $1000 \mathrm{~Hz}$ on each trial from the moment that the indicator started filling 
bioRxiv preprint doi: https://doi.org/10.1101/2020.12.11.422006; this version posted December 11, 2020. The copyright holder for this preprint (which was not certified by peer review) is the author/funder, who has granted bioRxiv a license to display the preprint in perpetuity. It is made available under aCC-BY-ND 4.0 International license.

for 1.5 seconds. Response times were recorded as the time between indicator fill onset and the

A

Go trial
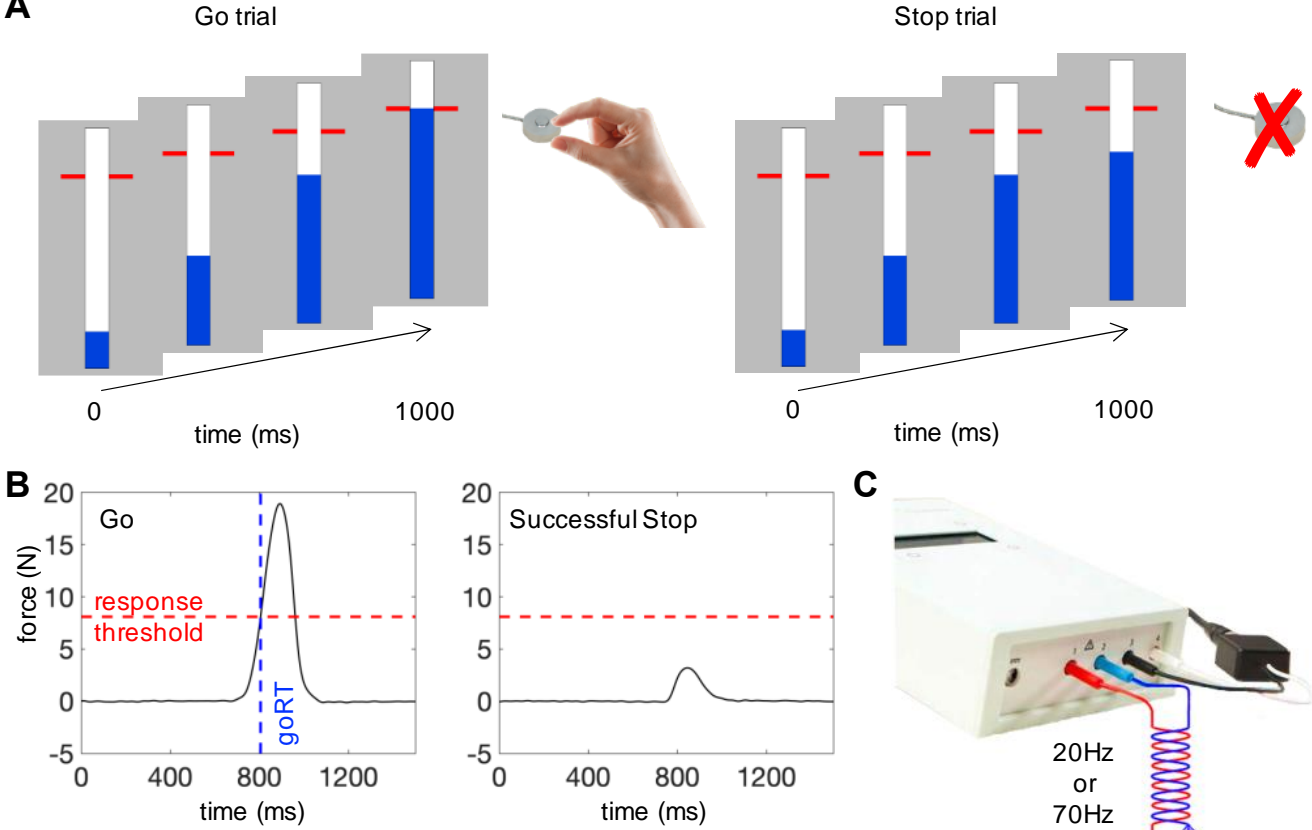

C

D
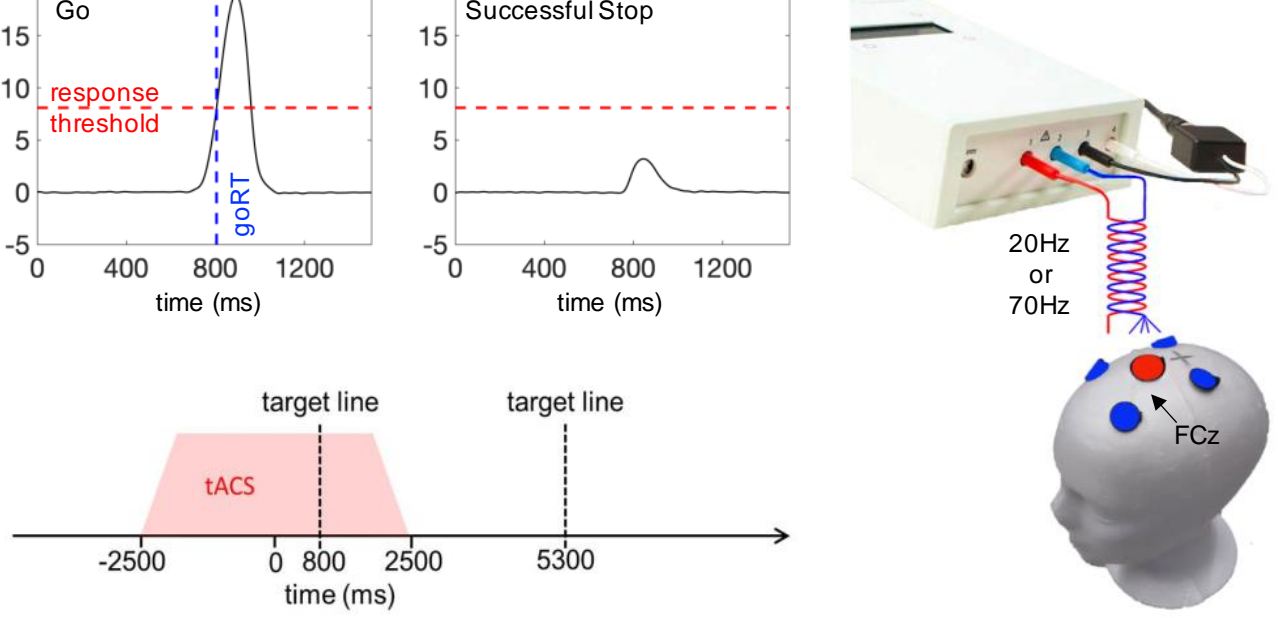

Figure 7. (A) Anticipated response version of stop-signal paradigm. An indicator (depicted in blue) increased from the bottom up at constant velocity reaching the top in $1 \mathrm{~s}$. In 'go' trials, participants had to stop the indicator as close as possible to the red target line by squeezing a force sensor. In 'stop' trials, the bar would stop filling before it reached the target line and participants were instructed to withhold their response. (B) Example force trace of a go trial and a successful stop with a partial response. Response times were recorded as the time between indicator fill onset and the moment the force signal first exceeded the response threshold ( $\sim 30 \%$ of maximum voluntary force). Stop trials were classified as failed stop trials if the force produced exceeded the response threshold. If the force remained below the threshold, the trial was classified as a successfully inhibited. (C) Electrode montage with center electrode $(\varnothing 2.5 \mathrm{~cm})$ over $\mathrm{FCz}$ and surrounding electrodes at $\sim 5 \mathrm{~cm}$ center-to-center distance $(\varnothing 2 \mathrm{~cm})$. (D) Event-related alternating current stimulation ensued randomly in $40 \%$ of the trials. Stimulation commenced $2.5 \mathrm{~s}$ before indicator fill onset and lasted for a total of $5 \mathrm{~s}$ including fading in/out phase of $0.5 \mathrm{~s}$. Between the end of the previous and the start of the next stimulation trains was a minimum interval of $4.5 \mathrm{~s}$. 


\section{tACS-EEG procedures}

2 EEG was recorded by means of an EGI 400 Geodesic system with a 128-channel HydroCel Geodesic

3 Sensor Net (EGI, Eugene, OR, USA) and a sampling rate of $1000 \mathrm{~Hz}$ (Net Station v5.1.2). Cz was used as physical reference during recording and impedance of all electrodes was kept below $50 \mathrm{k} \Omega$ as recommended for this system. The position of the electrodes on the participants scalp were localized with the Geodesic Photogrammetry System (GPS 2.0, EGI, Eugene, OR, USA). setup (DC Stimulator Plus, NeuroConn, Ilmenau, Germany) with a stimulation intensity of $1000 \mu \mathrm{A}$ (peak-to-peak amplitude). The target electrode $(2.5 \mathrm{~cm} \varnothing)$ was placed over the preSMA (FCz) (Homan et al., 1987), and the four surrounding electrodes $(2 \mathrm{~cm} \varnothing)$ were placed at positions F1, F2, C1 and C2 (Figure 7C). In all instances impedance of the tACS electrodes was kept below $10 \mathrm{k} \Omega$ (range $1.2-7 \mathrm{k} \Omega$, mean $3.51 \mathrm{k} \Omega$ ). tACS was applied in an event-related manner, distributed pseudo-randomly over $40 \%$ of both go and stop trials. Each stimulation train ramped up in $0.5 \mathrm{~s}, 2.5 \mathrm{~s}$ before the start of the trial and lasted a total of $4 \mathrm{~s}$ before ramping down again (Figure 7D). Between the end and the start of the next stimulation train was an interval of $4.5 \mathrm{~s}$ or $9 \mathrm{~s}$. Over one experimental session the participants received a total of $18 \mathrm{~min}$ of tACS.

For the first 16 participants, the classic HydroCel Geodesic Sensor Net was used in which the electrodes are encased in plastic cups covered with sponges that are soaked in electrolyte solution. To ensure good contact of the tACS electrodes a sponge soaked in the same electrolyte solution was placed under the rubber electrodes. With this set-up the tACS stimulation caused saturation of several EEG electrodes in about $1 / 3$ of the participants, resulting in large artefacts even during the nonstimulated periods. The remaining 20 participants were tested using HydroCel Geodesic Sensor Net 130 LTM nets, where the cups were filled with electrolyte gel (Redux ${ }^{\circledast}$, Parker Laboratories, Fairfield, NJ, USA), which resolved the saturation problems. The same gel was used to ensure a good contact between skin and tACS electrodes. 
bioRxiv preprint doi: https://doi.org/10.1101/2020.12.11.422006; this version posted December 11,2020 . The copyright holder for this preprint (which was not certified by peer review) is the author/funder, who has granted bioRxiv a license to display the preprint in perpetuity. It is made available under aCC-BY-ND 4.0 International license.

\section{Evaluation of subjective level of discomfort caused by tACS and self-perceived level of fatigue}

2 The level of discomfort was assessed after each session according to a Visual Analogue Scale (VAS) of

$310 \mathrm{~cm}$ length without numerical indication, extremes constituted 'absolutely no discomfort/pain' and

4 'worst discomfort/pain ever'. The point on the scale marked by the participant was subsequently converted into a score ranging from 1-10 (Huskisson, 1974). Similarly, participants evaluated their perceived level of fatigue with a VAS (ranging from 'absolutely not tired' to 'maximally tired/exhausted') at the beginning and end of each experimental session.

\section{Behavioral analysis}

9 Force data and response times were analyzed using Matlab R2016a (Mathworks, Natick, MA, USA).

Force data was filtered with a fifth-order $20 \mathrm{~Hz}$ low pass Butterworth filter, and baseline corrected by subtracting the average force between -650 to $-300 \mathrm{~ms}$ prior to the target. Per trial we determined: (i) peak force (i.e. maximum force in that trial), (ii) peak rate of force development, and (iii) the time to peak, which is defined as the time between the first instance that the force trace exceeds $5 *$ SD of the baseline period and the peak. On successful stop trials force production did not always exceed $5 *$ SD of the baseline period. To quantify this and to capture possible changes in the proportion of successful stop trials with 'perfect inhibition', we calculated the proportion of successful stop trials in which force production did exceed the threshold. Trials with extreme early responses ( $>400 \mathrm{~ms}$ before the target) and go trials where there was no response were considered errors, and trials with force output more than $2.5^{*} \mathrm{SD}$ from their respective mean were defined as outliers and removed. In addition to the average per trial type and condition, we also calculated the percent change in peak force, peak force rate, time to peak, and the proportion of successful stop trials in which the response exceeded $5 * S D$ of the baseline period between stimulated versus non-stimulated trials. 


\section{Response times}

2 Go trial response times (goRT) and response times for unsuccessful stop trials were determined relative to the target (time of response $-800 \mathrm{~ms}$ ). Early response times ( $>400 \mathrm{~ms}$ before the target) and go trials where there was no response were considered errors and removed. For stop trials, the probability of responding was calculated and stop signal reaction time (SSRT) was determined via the integration method in which go omissions were replaced with the maximum RT (1000ms) (Verbruggen et al., 2019).

\section{Computational modelling}

9 To gain insight into whether stimulation affected the processes underlying going and stopping, we fitted the stop accuracy and response time distributions to a dependent process model (DPM) with the Race Against Drift Diffusion toolbox (RADD v0.5.5) (Dunovan et al., 2015; Dunovan \& Verstynen, 2019). The DPM assumes that the execution process ( $\theta_{e}$ begins to accumulate after a delay (tr) until reaching an upper decision threshold (a), yielding a go response (Figure 2). The dynamics of $\theta_{e}$ are described by the stochastic differential equation, accumulating with a mean rate of $v_{e}$ (i.e., execution drift rate) and a standard deviation described by the dynamics of a white noise process $(d W)$ with diffusion constant $\sigma$ as follows:

$$
d \theta_{e}=v_{e} d t+\sigma d W
$$

In the event of a stop signal, the braking process $\left(\theta_{b}\right)$ is initiated at the current state of $\theta_{e}$ with a negative drift rate $\left(v_{b}\right)$. If $\theta_{b}$ reaches the 0 boundary before $\theta_{e}$ reaches the execution boundary no response is made. The change in $\theta_{b}$ over time is given by:

$$
d \theta_{b}=v_{b} d t+\sigma d W
$$

The dependency between $\theta_{e}$ and $\theta_{b}$ in model is implemented by declaring that the intial state of $\theta_{b}$ is equal to the state of $\theta_{e}$.

To determine if any of the model parameters (execution drift rate $\left(v_{e}\right)$, braking drift rate $\left(v_{b}\right)$, boundary height $(a)$ or execution onset delay $(t r))$ changed during stimulation we fitted four models to the average group data, each allowing only one of the parameters to vary for the within subject 
1 factors FREQUENCY $(2 \mathrm{~Hz}, 70 \mathrm{~Hz})$, and STIMULATION CONDITION (ON, OFF). The fitting procedure was

2 aimed at minimizing a cost function equal to the sum of the squared and weighted errors between

3 vectors of observed and simulated response probabilities, stop accuracy and response time quantiles of correct go responses and failed stop responses (error RT). To obtain an estimate of fit reliability for each model, we restarted the fitting procedure from 20 randomly sampled sets of initial parameter values (based on 2000 sampled parameter sets). All fits were initialized from multiple starting values in steps (step size .05) to avoid biasing model selection to unfair advantages in the initial settings. Each initial set was then optimized using a basinhopping algorithm to find the region of global minimum followed by a Nelder-Mead simplex optimization for fine-tuning globally optimized parameter values. The simplex-optimized parameter estimates were then held constant, except for the designated parameter that was submitted to a second simplex run to find the best fitting values for the four conditions. Finally, the model fits were compared in goodness-of-fit with the Akaike information criterion (AIC) and Bayesian information criterion (BIC). A difference of $\mathrm{AIC} / \mathrm{BIC}$ between $3-10$ is considered moderate evidence for one model over the other and $>10$ as strong evidence (Lee \& Wagenmakers, 2014). For more details on model fitting, model code, simulation, cost function weights, and animations see Dunovan et al. 2015, 2019 and https://www.github.com/coaxlab/radd.

\section{Electrical field modeling}

For the last 20 participants, a Philips 3T MRI scanner with a 32-channel head coil was used to acquire high resolution T1 and T2-weighted images, with and without fat suppression (4 scans in total). T1weighted structural images were acquired using magnetization prepared rapid gradient echo (MPRAGE; TR=9.60ms, TE=4.60ms, 222 sagittal slices, $0.98 \times 0.98 \times 1.2 \mathrm{~mm}$ voxels). T2-weighted structural images were acquired with $T R=2500 \mathrm{~ms}, T E=203 \mathrm{~ms}, 200$ sagittal slices, $1.02 \times 1.01 \times 1 \mathrm{~mm}$ voxels. To simulate the electrical field expansion of the 1-by-4 electrode montage, computational modeling was performed (www.simnibs.org) using a finite element head model derived from the four T1 and T2 scans of each individual (Opitz et al., 2015). All electrodes were modeled as a $2 \mathrm{~mm}$ thick rubber layer (conductivity $0.1 \mathrm{~S} / \mathrm{m}$ ) with a $1 \mathrm{~mm}$ thick layer of conductive gel underneath (conductivity 
of $3 \mathrm{~S} / \mathrm{m}$, as stated by the manufacturer). The positions of the tACS electrodes were determined based on the localization of the EEG electrode positions of all 128 sensors and three landmarks positions (nasion, left and right preauricular). Also the positions of the connectors were explicitly modeled (modeling procedure described in detail in Saturnino et al. (2015)). A current strength of $500 \mu \mathrm{A}$ was simulated, corresponding to $1000 \mu \mathrm{A}$ peak-to-peak amplitude. Finally, the normalized predicted electric field distribution mesh was converted to nifti (https://github.com/ncullen93/mesh2nifti). of stimulation on behavior, the normalized electrical field strength was extracted for the region of interest. This was done as follows: A ROI was created based on peak fMRI activation coordinates (contrast stop>go) in previous studies using the same paradigm (Coxon et al., 2016; Leunissen et al., 2016)(sphere with $10 \mathrm{~mm}$ diameter centered around the coordinate [11, 10,62] of the Montreal National Institute (MNI) space). The ROI was transformed into subject space using the inverse of the deformation fields generated by the simnibs pipeline. Average normalized predicted electric field in the resulting individual preSMA ROIs of each session were related to the percent change in force during beta and gamma stimulation using linear regression.

\section{EEG analysis}

EEG data was analyzed using the FieldTrip toolbox for EEG/MEG-analysis (Oostenveld et al., 2011). EEG during no stimulation trials was only analyzed in the last 20 participants due to the high amount of data loss in the first 16 (see tACS-EEG procedures). Pre- and post-tACS resting EEG recordings were available for all 36 participants. Since non-neural signals contaminate the low amplitude gamma-band activity in scalp EEG all analyses only focus on beta-band activity (Muthukumaraswamy, 2013).

Pre- and post-tACS resting EEG recordings were re-referenced to the average reference. Bad channels were rejected upon visual inspection. Subsequently, the data was band-pass filtered at $1-100 \mathrm{~Hz}$. Independent component analysis was used to identify ocular artifacts, which were then projected out 
1 to the horizontal and vertical electro-oculogram (see supplementary material). Finally, the data was epoched in 1s segments and bad segments were rejected upon visual inspection. A fast Fourier transformation (FFT) for frequencies between 4 and $45 \mathrm{~Hz}$ was performed on the first 100 artifact-free segments using a Hanning window and 10s zero-padding. trend (least-squares fit) to the log-transformed spectrum (Haegens et al., 2014; Nikulin \& Brismar, 2006). Subsequently, a $3^{\text {rd }}$ order Gaussian curve was fitted to the power spectra to estimate the individual peak frequency. percent change in mean power at $13-30 \mathrm{~Hz}$ in the averaged pre and post spectra.

\section{Task performance in tACS-free intervals}

13 To capture potential differences in event-related synchronization or desynchronization (ERS/ERD) we extracted $2 \mathrm{~s}$ before and $0.7 \mathrm{~s}$ after the stop signal presentation. Epochs were re-referenced to the average reference and noisy channels and epochs were rejected upon visual inspection. Independent component analysis was used to identify ocular artifacts, which were then projected out of the data

(see resting EEG measurements). EEG data of one participant had to be discarded due to excessive (eye)movements. Subsequently, the data was band-pass filtered between $1-100 \mathrm{~Hz}$. To avoid boundary jumps caused by the filtering procedure the first and last 300ms of the epochs were discarded. Complex Fourier spectra were extracted with Morlet wavelets between 4 and $45 \mathrm{~Hz}$ with step size of $0.5 \mathrm{~Hz}$ and a fixed width of 7 cycles. The resulting absolute time-frequency spectra were averaged per condition and the conditions were compared with a dependent-sample cluster-based permutation t-test (two-tailed, 5000 permutations, cluster alpha of 0.05 ). This procedure ensures correction for multiple comparisons over time and frequencies (Maris \& Oostenveld, 2007). 
1 frequency range $(13-30 \mathrm{~Hz})$. An FDR correction (alpha 0.05$)$ was applied for correcting for testing

2 multiple time points.

\section{Statistical analysis}

4 All statistical analyses were performed with R version 4.0.0 (R Core Team, 2020) using packages nlme version 3.1-147 (Pinheiro et al., 2020) and multcomp version 1.4-13 (Hothorn et al., 2008). given as Type III sums of squares for sequentially fitted fixed effects ( $F, d f, p)$. Significant results from simultaneous pairwise post-hoc comparisons with Tukey contrasts are reported with adjusted $p$ values for estimates of contrasts (estimated mean difference $\pm S E, z$-value, adjusted $p_{\text {Tukey }}$ ). trials was significantly different from zero using a two-tailed one-sample t-test. normalized electrical field strength.

$70 \mathrm{~Hz}$ sessions were compared with the Wilcoxon signed-rank test. post) on subjective level of stimulation-related discomfort (VAS discomfort) and subjective level of fatigue (VAS $\left._{\text {fatigue }}\right)$ were analyzed with a repeated measures ANOVA. 


\section{Acknowledgments}

2 This work was supported by the Internal Research Fund KU Leuven (C16/15/070), Research

3 Foundation Flanders (FWO) grants (G089818N, G0F7616N, G093616N, 1005018N) and an Excellence of Science grant (EOS 30446199, MEMODYN). IL is supported by an individual fellowship of the FWO (12M6718N) and EU (MSCA 798619). JC is supported by the Australian Research Council (ARC DP200100234 and DP180102066).

\section{Competing interests}

8 The authors declare no competing interests.

\section{References}

Alegre, M., Lopez-Azcarate, J., Obeso, I., Wilkinson, L., Rodriguez-Oroz, M. C., Valencia, M., .. Obeso, J. A. (2013). The subthalamic nucleus is involved in successful inhibition in the stop-signal task: a local field potential study in Parkinson's disease. Exp Neurol, 239, 1-12. doi:10.1016/j.expneurol.2012.08.027

Ali, M. M., Sellers, K. K., \& Frohlich, F. (2013). Transcranial alternating current stimulation modulates large-scale cortical network activity by network resonance. J Neurosci, 33(27), 11262-11275. doi:10.1523/JNEUROSCI.5867-12.2013

Aron, A. R., Herz, D. M., Brown, P., Forstmann, B. U., \& Zaghloul, K. (2016). Frontosubthalamic Circuits for Control of Action and Cognition. J Neurosci, 36(45), 11489-11495. doi:10.1523/JNEUROSCI.234816.2016

Bartoli, E., Aron, A. R., \& Tandon, N. (2018). Topography and timing of activity in right inferior frontal cortex and anterior insula for stopping movement. Hum Brain Mapp, 39(1), 189-203. doi:10.1002/hbm.23835

Bestmann, S., \& Ward, N. (2017). Are current flow models for transcranial electrical stimulation fit for purpose? Brain Stimul, 10(4), 865-866. doi:10.1016/j.brs.2017.04.002

Bikson, M., Datta, A., \& Elwassif, M. (2009). Establishing safety limits for transcranial direct current stimulation. Clin Neurophysiol, 120(6), 1033-1034. doi:10.1016/j.clinph.2009.03.018

Bissett, P. G., \& Logan, G. D. (2012). Post-stop-signal slowing: strategies dominate reflexes and implicit learning. J Exp Psychol Hum Percept Perform, 38(3), 746-757. doi:10.1037/a0025429

Boucher, L., Palmeri, T. J., Logan, G. D., \& Schall, J. D. (2007). Inhibitory control in mind and brain: an interactive race model of countermanding saccades. Psychol Rev, 114(2), 376-397. doi:10.1037/0033295X.114.2.376 
Castiglione, A., Wagner, J., Anderson, M., \& Aron, A. R. (2019). Preventing a Thought from Coming to Mind Elicits Increased Right Frontal Beta Just as Stopping Action Does. Cereb Cortex, 29(5), 2160-2172. doi:10.1093/cercor/bhz017

4 Chakarov, V., Naranjo, J. R., Schulte-Monting, J., Omlor, W., Huethe, F., \& Kristeva, R. (2009). Beta5 range EEG-EMG coherence with isometric compensation for increasing modulated low-level forces. $J$ 6 Neurophysiol, 102(2), 1115-1120. doi:10.1152/jn.91095.2008

7 Coxon, J. P., Goble, D. J., Leunissen, I., Van Impe, A., Wenderoth, N., \& Swinnen, S. P. (2016). Functional 8 Brain Activation Associated with Inhibitory Control Deficits in Older Adults. Cereb Cortex, 26(1), 12-22. 9 doi:10.1093/cercor/bhu165 of prepared action. J Neurophysiol, 95(6), 3371-3383. doi:10.1152/jn.01334.2005 sensorimotor cortex with electrocorticographic spectral analysis. II. Event-related synchronization in the gamma band. Brain, 121 ( Pt 12), 2301-2315. doi:10.1093/brain/121.12.2301 Models. Front Psychiatry, 3, 91. doi:10.3389/fpsyt.2012.00091

Dunovan, K., Lynch, B., Molesworth, T., \& Verstynen, T. (2015). Competing basal ganglia pathways determine the difference between stopping and deciding not to go. Elife, 4, e08723. doi:10.7554/eLife.08723 doi:10.1523/JNEUROSCI.1924-18.2019 20(2), 156-165. doi:10.1016/j.conb.2010.02.015 
Fries, P. (2005). A mechanism for cognitive dynamics: neuronal communication through neuronal coherence. Trends Cogn Sci, 9(10), 474-480. doi:10.1016/j.tics.2005.08.011 Effects of Transcranial Alternating Current Stimulation on Repetitive Finger Movements in Healthy Humans. Neural Plast, 2018, 4593095. doi:10.1155/2018/4593095 variability in alpha peak frequency. Neuroimage, 92, 46-55. doi:10.1016/j.neuroimage.2014.01.049

Heise, K. F., Kortzorg, N., Saturnino, G. B., Fujiyama, H., Cuypers, K., Thielscher, A., \& Swinnen, S. P. (2016). Evaluation of a Modified High-Definition Electrode Montage for Transcranial Alternating Current Stimulation (tACS) of Pre-Central Areas. Brain Stimul, 9(5), 700-704. doi:10.1016/j.brs.2016.04.009 offline effects of alpha and beta transcranial alternating current stimulation (tACS) on continuous bimanual performance and task-set switching. Sci Rep, 9(1), 3144. doi:10.1038/s41598-019-39900-0

Helfrich, R. F., Schneider, T. R., Rach, S., Trautmann-Lengsfeld, S. A., Engel, A. K., \& Herrmann, C. S. (2014). Entrainment of brain oscillations by transcranial alternating current stimulation. Curr Biol, 24(3), 333-339. doi:10.1016/j.cub.2013.12.041

Herrmann, C. S., Struber, D., Helfrich, R. F., \& Engel, A. K. (2016). EEG oscillations: From correlation to causality. Int J Psychophysiol, 103, 12-21. doi:10.1016/j.ijpsycho.2015.02.003

Homan, R. W., Herman, J., \& Purdy, P. (1987). Cerebral location of international 10-20 system electrode placement. Electroencephalogr Clin Neurophysiol, 66(4), 376-382. doi:10.1016/00134694(87)90206-9

Hosaka, R., Nakajima, T., Aihara, K., Yamaguchi, Y., \& Mushiake, H. (2016). The Suppression of Beta Oscillations in the Primate Supplementary Motor Complex Reflects a Volatile State During the Updating of Action Sequences. Cereb Cortex, 26(8), 3442-3452. doi:10.1093/cercor/bhv163

Hothorn, T., Bretz, F., \& Westfall, P. (2008). Simultaneous Inference in General Parametric Models. Biometrical Journal, 50(3), 346-363.

Huang, Y., Liu, A. A., Lafon, B., Friedman, D., Dayan, M., Wang, X., .. Parra, L. C. (2017). Measurements and models of electric fields in the in vivo human brain during transcranial electric stimulation. Elife, 6. doi:10.7554/eLife.18834

Huskisson, E. C. (1974). Measurement of pain. Lancet, 2(7889), 1127-1131. doi:10.1016/s01406736(74)90884-8

Huster, R. J., Schneider, S., Lavallee, C. F., Enriquez-Geppert, S., \& Herrmann, C. S. (2017). Filling the void-enriching the feature space of successful stopping. Hum Brain Mapp, 38(3), 1333-1346. doi:10.1002/hbm.23457 
Jahanshahi, M., Obeso, I., Rothwell, J. C., \& Obeso, J. A. (2015). A fronto-striato-subthalamic-pallidal network for goal-directed and habitual inhibition. Nat Rev Neurosci, 16(12), 719-732. doi:10.1038/nrn4038

4 Jha, A., Nachev, P., Barnes, G., Husain, M., Brown, P., \& Litvak, V. (2015). The Frontal Control of 5 Stopping. Cereb Cortex, 25(11), 4392-4406. doi:10.1093/cercor/bhv027

Joundi, R. A., Jenkinson, N., Brittain, J. S., Aziz, T. Z., \& Brown, P. (2012). Driving oscillatory activity in the human cortex enhances motor performance. Curr Biol, 22(5), 403-407. doi:10.1016/j.cub.2012.01.024 oscillatory activity correlates with clinical improvement in Parkinson's disease. Eur J Neurosci, 23(7), 1956-1960. doi:10.1111/j.1460-9568.2006.04717.x Event-related beta desynchronization in human subthalamic nucleus correlates with motor performance. Brain, 127(Pt 4), 735-746. doi:10.1093/brain/awh106

Lee, M. D., \& Wagenmakers, E. J. (2014). Bayesian Cognitive Modeling: A Practical Course. Cambridge:

Leunissen, I., Coxon, J. P., \& Swinnen, S. P. (2016). A proactive task set influences how response inhibition is implemented in the basal ganglia. Hum Brain Mapp, 37(12), 4706-4717. doi:10.1002/hbm.23338 of inhibitory efficiency: to anticipate, choose or simply react? Eur J Neurosci, 45(12), 1512-1523. doi:10.1111/ejn.13590

Litvak, V., Eusebio, A., Jha, A., Oostenveld, R., Barnes, G., Foltynie, T., . . Brown, P. (2012). Movementrelated changes in local and long-range synchronization in Parkinson's disease revealed by simultaneous magnetoencephalography and intracranial recordings. J Neurosci, 32(31), 10541-10553. doi:10.1523/JNEUROSCI.0767-12.2012 
Moisa, M., Polania, R., Grueschow, M., \& Ruff, C. C. (2016). Brain Network Mechanisms Underlying Motor Enhancement by Transcranial Entrainment of Gamma Oscillations. J Neurosci, 36(47), 1205312065. doi:10.1523/JNEUROSCI.2044-16.2016

4

5

6

Munoz, D. P., \& Schall, J. D. (2003). Concurrent, distributed control of saccade initiation in the frontal eye field and superior colliculus. In W. T. Hall \& A. Moschovakis (Eds.), The superior colliculus: New approaches for studying sensorimotor integration (pp. 55-82). New York: CRC Press.

Muthukumaraswamy, S. D. (2010). Functional properties of human primary motor cortex gamma oscillations. J Neurophysiol, 104(5), 2873-2885. doi:10.1152/jn.00607.2010

Muthukumaraswamy, S. D. (2013). High-frequency brain activity and muscle artifacts in MEG/EEG: a review and recommendations. Front Hum Neurosci, 7, 138. doi:10.3389/fnhum.2013.00138

Nachev, P., Kennard, C., \& Husain, M. (2008). Functional role of the supplementary and presupplementary motor areas. Nat Rev Neurosci, 9(11), 856-869. doi:10.1038/nrn2478

Neuling, T., Ruhnau, P., Weisz, N., Herrmann, C. S., \& Demarchi, G. (2017). Faith and oscillations recovered: On analyzing EEG/MEG signals during tACS. Neuroimage, 147, 960-963. doi:10.1016/j.neuroimage.2016.11.022

Nikulin, V. V., \& Brismar, T. (2006). Phase synchronization between alpha and beta oscillations in the human electroencephalogram. Neuroscience, 137(2), 647-657. doi:10.1016/j.neuroscience.2005.10.031

Noury, N., \& Siegel, M. (2018). Analyzing EEG and MEG signals recorded during tES, a reply. Neuroimage, 167, 53-61. doi:10.1016/j.neuroimage.2017.11.023

Nowak, M., Zich, C., \& Stagg, C. J. (2018). Motor Cortical Gamma Oscillations: What Have We Learnt and Where Are We Headed? Curr Behav Neurosci Rep, 5(2), 136-142. doi:10.1007/s40473-018-0151$\mathrm{z}$

Oldfield, R. C. (1971). The assessment and analysis of handedness: the Edinburgh inventory. Neuropsychologia, 9(1), 97-113. doi:10.1016/0028-3932(71)90067-4

Oostenveld, R., Fries, P., Maris, E., \& Schoffelen, J. M. (2011). FieldTrip: Open source software for advanced analysis of MEG, EEG, and invasive electrophysiological data. Comput Intell Neurosci, 2011, 156869. doi:10.1155/2011/156869

Opitz, A., Falchier, A., Yan, C. G., Yeagle, E. M., Linn, G. S., Megevand, P., . . Schroeder, C. E. (2016). Spatiotemporal structure of intracranial electric fields induced by transcranial electric stimulation in humans and nonhuman primates. Sci Rep, 6, 31236. doi:10.1038/srep31236

Opitz, A., Paulus, W., Will, S., Antunes, A., \& Thielscher, A. (2015). Determinants of the electric field during transcranial direct current stimulation. Neuroimage, 109, 140-150. doi:10.1016/j.neuroimage.2015.01.033 
1 Pinheiro, J., Bates, D., DebRoy, S., Sarkar, D., \& Team, R. C. (2020). Linear and Nonlinear Mixed Effects

2 Models. Retrieved from https://CRAN.R-project.org/package=nlme>.

3 Pogosyan, A., Gaynor, L. D., Eusebio, A., \& Brown, P. (2009). Boosting cortical activity at Beta-band

4 frequencies slows movement in humans. Curr Biol, 19(19), 1637-1641. doi:10.1016/j.cub.2009.07.074

5 R Core Team. (2020). R: A language and environment for statistical computing. https://www.R-

6 project.org/: R Foundation for Statistical Computing.

7 Raud, L., Westerhausen, R., Dooley, N., \& Huster, R. J. (2020). Differences in unity: The go/no-go and

8 stop signal tasks rely on different mechanisms. Neuroimage, 210, 116582.

9 doi:10.1016/j.neuroimage.2020.116582

10

11

Ray, N. J., Brittain, J. S., Holland, P., Joundi, R. A., Stein, J. F., Aziz, T. Z., \& Jenkinson, N. (2012). The role of the subthalamic nucleus in response inhibition: evidence from local field potential recordings in the human subthalamic nucleus. Neuroimage, 60(1), 271-278. doi:10.1016/j.neuroimage.2011.12.035

Saturnino, G. B., Antunes, A., \& Thielscher, A. (2015). On the importance of electrode parameters for shaping electric field patterns generated by tDCS. Neuroimage, 120, 25-35. doi:10.1016/j.neuroimage.2015.06.067

Schmidt, R., Herrojo Ruiz, M., Kilavik, B. E., Lundqvist, M., Starr, P. A., \& Aron, A. R. (2019). Beta Oscillations in Working Memory, Executive Control of Movement and Thought, and Sensorimotor Function. J Neurosci, 39(42), 8231-8238. doi:10.1523/JNEUROSCI.1163-19.2019

Schmidt, R., Leventhal, D. K., Mallet, N., Chen, F., \& Berke, J. D. (2013). Canceling actions involves a race between basal ganglia pathways. Nat Neurosci, 16(8), 1118-1124. doi:10.1038/nn.3456

Slater-Hammel, A. T. (1960). Reliability, Accuracy, and Refractoriness of a Transit Reaction. The Research Quarterly, 31(2), 217-228.

Stinear, C. M., Coxon, J. P., \& Byblow, W. D. (2009). Primary motor cortex and movement prevention: where Stop meets Go. Neurosci Biobehav Rev, 33(5), 662-673. doi:10.1016/j.neubiorev.2008.08.013

Sundby, K. K., Jana, S., \& Aron, A. R. (2020). Double blind disruption of right inferior frontal cortex with TMS reduces right frontal beta power for action-stopping. J Neurophysiol. doi:10.1152/jn.00459.2020

Swann, N., Tandon, N., Canolty, R., Ellmore, T. M., McEvoy, L. K., Dreyer, S., . . Aron, A. R. (2009). Intracranial EEG reveals a time- and frequency-specific role for the right inferior frontal gyrus and primary motor cortex in stopping initiated responses. J Neurosci, 29(40), 12675-12685. doi:10.1523/JNEUROSCI.3359-09.2009

Swann, N. C., Cai, W., Conner, C. R., Pieters, T. A., Claffey, M. P., George, J. S., . . Tandon, N. (2012). Roles for the pre-supplementary motor area and the right inferior frontal gyrus in stopping action: electrophysiological responses and functional and structural connectivity. Neuroimage, 59(3), 28602870. doi:10.1016/j.neuroimage.2011.09.049 
Szmalec, A., Demanet, J., Vandierendonck, A., \& Verbruggen, F. (2009). Investigating the role of conflict resolution in memory updating by means of the one-back choice RT task. Psychol Res, 73(3), 390-406. doi:10.1007/s00426-008-0149-3

4

5

6

Tan, J., Wansbrough, K., Williams, A. G., Nitsche, M. A., Vallence, A. M., \& Fujiyama, H. (2020). The importance of model-driven approaches to set stimulation intensity for multi-channel transcranial alternating current stimulation (tACS). Brain Stimul, 13(4), 1002-1004. doi:10.1016/j.brs.2020.04.001

Thut, G., Schyns, P. G., \& Gross, J. (2011). Entrainment of perceptually relevant brain oscillations by non-invasive rhythmic stimulation of the human brain. Front Psychol, 2, 170. doi:10.3389/fpsyg.2011.00170

van den Wildenberg, W. P., van Boxtel, G. J., \& van der Molen, M. W. (2003). The duration of response inhibition in the stop-signal paradigm varies with response force. Acta Psychol (Amst), 114(2), 115129. doi:10.1016/s0001-6918(03)00062-3

Veniero, D., Vossen, A., Gross, J., \& Thut, G. (2015). Lasting EEG/MEG Aftereffects of Rhythmic Transcranial Brain Stimulation: Level of Control Over Oscillatory Network Activity. Front Cell Neurosci, 9, 477. doi:10.3389/fncel.2015.00477

Verbruggen, F., Aron, A. R., Band, G. P., Beste, C., Bissett, P. G., Brockett, A. T., . . Boehler, C. N. (2019). A consensus guide to capturing the ability to inhibit actions and impulsive behaviors in the stop-signal task. Elife, 8. doi:10.7554/eLife.46323

Vossen, A., Gross, J., \& Thut, G. (2015). Alpha Power Increase After Transcranial Alternating Current Stimulation at Alpha Frequency (alpha-tACS) Reflects Plastic Changes Rather Than Entrainment. Brain Stimul, 8(3), 499-508. doi:10.1016/j.brs.2014.12.004

Wach, C., Krause, V., Moliadze, V., Paulus, W., Schnitzler, A., \& Pollok, B. (2013). The effect of $10 \mathrm{~Hz}$ transcranial alternating current stimulation (tACS) on corticomuscular coherence. Front Hum Neurosci, 7, 511. doi:10.3389/fnhum.2013.00511

Wagner, J., Wessel, J. R., Ghahremani, A., \& Aron, A. R. (2018). Establishing a Right Frontal Beta Signature for Stopping Action in Scalp EEG: Implications for Testing Inhibitory Control in Other Task Contexts. J Cogn Neurosci, 30(1), 107-118. doi:10.1162/jocn_a_01183

Wessel, J. R., Conner, C. R., Aron, A. R., \& Tandon, N. (2013). Chronometric electrical stimulation of right inferior frontal cortex increases motor braking. J Neurosci, 33(50), 19611-19619. doi:10.1523/JNEUROSCI.3468-13.2013

Wessel, J. R., Ghahremani, A., Udupa, K., Saha, U., Kalia, S. K., Hodaie, M., . . Chen, R. (2016). Stoprelated subthalamic beta activity indexes global motor suppression in Parkinson's disease. Mov Disord, 31(12), 1846-1853. doi:10.1002/mds.26732

Wischnewski, M., Engelhardt, M., Salehinejad, M. A., Schutter, D., Kuo, M. F., \& Nitsche, M. A. (2019a). NMDA Receptor-Mediated Motor Cortex Plasticity After $20 \mathrm{~Hz}$ Transcranial Alternating Current Stimulation. Cereb Cortex, 29(7), 2924-2931. doi:10.1093/cercor/bhy160 
1 Wischnewski, M., Schutter, D., \& Nitsche, M. A. (2019b). Effects of beta-tACS on corticospinal

2 excitability: A meta-analysis. Brain Stimul, 12(6), 1381-1389. doi:10.1016/j.brs.2019.07.023

3 Woods, A. J., Antal, A., Bikson, M., Boggio, P. S., Brunoni, A. R., Celnik, P., . . Nitsche, M. A. (2016). A

4 technical guide to tDCS, and related non-invasive brain stimulation tools. Clin Neurophysiol, 127(2),

5 1031-1048. doi:10.1016/j.clinph.2015.11.012

6 Zaehle, T., Rach, S., \& Herrmann, C. S. (2010). Transcranial alternating current stimulation enhances 7 individual alpha activity in human EEG. PLoS One, 5(11), e13766. doi:10.1371/journal.pone.0013766 